\title{
Monocyte chemoattractant protein-1 promotes the proliferation, migration and differentiation potential of fibroblast-like synoviocytes via the PI3K/P38 cellular signaling pathway
}

\author{
XIANG TONG ${ }^{1}$, HUANGJIAN ZENG ${ }^{1}$, PENGCHEN GU ${ }^{1}$, KAI WANG $^{1}$, HAN ZHANG $^{2}$ and XIANGJIN LIN ${ }^{1}$ \\ Departments of ${ }^{1}$ Orthopedic Surgery and ${ }^{2}$ Pathology, The First Affiliated Hospital, College of Medicine, \\ Zhejiang University, Hangzhou, Zhejiang 310003, P.R. China
}

Received April 27, 2019; Accepted November 6, 2019

DOI: $10.3892 / \mathrm{mmr} .2020 .10969$

\begin{abstract}
Rheumatoid arthritis (RA) is an autoimmune disease characterized by chronic inflammation of the joints and joint destruction. Monocyte chemoattractant protein 1 (MCP-1) is highly expressed in the joints of patients suffering from RA. The present study aimed to evaluate the effects of MCP-1 on the phenotype of fibroblast-like synoviocytes (FLSs) and their differentiation potential towards vascular endothelial cells. The expression of MCP-1 in collagen-induced arthritis (CIA) rats was investigated by PCR, ELISA and immunohistology. Cell proliferation induced by MCP-1 was measured using a Cell Counting Kit-8 (CCK-8) and 5-Bromo-2-deoxyuridine ELISA assay. In addition, the effects of MCP-1 on the migration of FLSs was examined using a Transwell assay. Activation of PI3K and P38 were investigated by western blotting following MCP-1 treatment. The vascular endothelial cell markers, tumor necrosis factor $\alpha$ (TNF- $\alpha)$ and interleukin-1 $\beta$ (IL- $\beta$ ), were also examined by western blotting. LY294002 [PI3K inhibitor, (LY)] and SB203580 [P38 inhibitor, (SB)] were used to examine the proliferative and pro-differentiation effect of $\mathrm{PI} 3 \mathrm{~K}$ and $\mathrm{P} 38$. The present findings showed that the expression level of MCP-1 in the synovium of CIA rats was significantly higher compared with controls. The present in vitro study suggested that MCP-1 increased the FLSs cell numbers with a maximal effect at $200 \mathrm{ng} / \mathrm{ml}$, and
\end{abstract}

Correspondence to: Dr Xiangjin Lin, Department of Orthopedic Surgery, The First Affiliated Hospital, College of Medicine, Zhejiang University, Building 3-5, 79 Qingchun Road, Hangzhou, Zhejiang 310003, P.R. China

E-mail: 1184016@zju.edu.cn; doclinxiangjin@163.com

Abbreviations: CIA, collagen-induced arthritis; FLS, fibroblastlike synoviocyte; IL-1 $\beta$, interleukin-1 $\beta$; LY, LY294002; MCP-1, monocyte chemoattractant protein-1; RA, rheumatoid arthritis; SB, SB203580; TNF- $\alpha$, tumor necrosis factor- $\alpha$; VEGF, vascular endothelial growth factor

Key words: RA, CIA, MCP-1, FLSs, proliferation, migration, differentiation, CD31, VEGF, angiogenesis, synovial hyperplasia induced the maximal phosphorylation of PI3K at $15 \mathrm{~min}$ and P38 at 30 min. In addition, MCP-1 stimulation significantly increased the migration of FLSs. Furthermore, MCP-1-induced the expression of vascular endothelial growth factor and CD31 in FLSs. Suppression of PI3K and P38 was found to reduce MCP-1 induced FLSs proliferation and migration, and decreased the expression levels of angiogenesis markers increased following MCP-1 treatment. MCP-1 was also found to increase the expression levels of both TNF- $\alpha$ and IL- $\beta$. Therefore, MCP-1 could promote the proliferation and migration of FLSs, and was found to increase the expression levels of various angiogenesis markers via PI3K/P38, suggesting a role for this pathway in synovium hyperplasia in RA.

\section{Introduction}

Rheumatoid arthritis (RA) is an autoimmune disease characterized by chronic inflammation of joints, leading to progressive and irreversible joint destruction $(1,2)$. The major events in RA are the hyperplasia of the synovial tissue, which leads to the formation of a pannus, and the release of proinflammatory cytokines (3). The aggressive pannus invades and destroys cartilage and bone, therefore playing a vital role in the pathogenesis of RA $(3,4)$. The pannus is mainly comprised of fibroblast-like synoviocytes (FLSs) and infiltration of lymphocytes and macrophages (5).

FLSs serve an essential role in the progression of RA, important components of the invasive hypertrophied pannus (6). The phenotype of FLSs in RA patients are similar to the phenotype of tumor cells, demonstrating pro-migratory and pro-invasive properties, which result in joint cartilage and bone destruction (6-8). Several cytokines destroy joints by activating proliferation and migratory pathways of FLS; for example, tumor necrosis factor (TNF) receptor-associated factor six can promote the migration capacity of FLSs in patients with RA (9). Transcription factor SRY-Box 5 (SOX5) is involved in joint destruction in collagen-induced arthritis (CIA) animal models, as SOX5 can increase the migration and invasion of FLSs (10). Interferon- $\gamma$ can stimulate the differentiation of FLSs into immune effector cells in Lyme arthritis, an autoimmune disease like RA (11). Therefore, investigating the mechanisms underlying the migration and invasion of 
FLSs is crucial to understand RA pathogenesis, and for the development of therapeutics for RA.

Accumulating evidence demonstrated that monocyte chemoattractant protein 1 (MCP-1) is highly expressed in the joints of patients suffering from RA (12-15). MCP-1 is a chemokine, and has been detected in endothelial cells, epithelial cells, fibroblasts, monocyte-macrophages and vascular smooth muscle cells (16). MCP-1 serves a major role in inflammation by attracting monocytes and macrophages (16). A previous study assessing 92 subjects showed that MCP-1 was higher among patients who developed RA compared with controls (17). A previous study using a CIA animal model suggested that MCP-1 can destroy joints via the recruitment of monocytes (18). Furthermore, the inhibition of MCP-1 with P8A-MCP-1, after the onset of arthritis, ameliorated joint inflammation and decreased macrophage accumulation, cytokine expression and p38MAPK activation (19).

Although MCP-1 is critical to the development and progression of arthritis, it is unclear whether MCP-1 destroys joint by changing the function of FLSs, including their proliferation, invasion and differentiation potential. MCP-1 has the potential to change the phenotype of many cells, such as their invasion capacity and differentiation potentials (20-22). MCP-1 was found to stimulate the proliferation and migration capacity of renal carcinoma cells (20). Additionally, MCP-1 induced in the herniated nucleus pulposus was identified to enhance osteoclastogenesis in the vertebral column, resulting in increased bone erosion (22). Furthermore, MCP-1 can mediate angiogenesis and tumor progression via vascular endothelial growth factor (VEGF) in vitro and in vivo (21). Targeted inhibition of MCP-1 decreases the development and mobilization of endothelial precursor cells, thereby blocking tumor neovascularization of mammary tumors (23).

Since MCP-1 plays an important role in the migration and invasion of tumor cells, in the present study it was hypothesized that MCP-1 may affect the phenotype of FLSs and subsequently participate in the hypertrophy and angiogenesis of the pannus during joint destruction in RA. Therefore, the aims of the present study were as followed: i) To investigate the effect of MCP-1 on the proliferation and migration of FLSs; ii) to investigate the effect of MCP-1 on the differentiation potential of FLSs towards endothelial cells; and iii) to investigate the signaling pathways downstream of MCP-1 affecting the cell proliferation, migration and differentiation of FLSs.

\section{Materials and methods}

Induction of collagen-induced arthritis (CIA) model. All experiments were carried out following the Guide for the Care and Use of Laboratory Animals of the National Institutes of Health and all the procedures were pre-approved by the Review Board of the First Affiliated Hospital of Medical College of Zhejiang University. Male Sprague-Dawley rats $(n=14$; age, 8 weeks; weight, $250 \mathrm{~g}$ ) were purchased from Zhejiang University. The rats were housed under standardized conditions with a 12-h light-dark cycle at $25^{\circ} \mathrm{C}$ and $45 \%$ humidity, with free access to sterilized water and pellet food. CIA was induced by immunization with bovine type II collagen (cat. no. 20021; Chondrex, Inc.). Rats were anesthetized using $1 \%$ sodium pentobarbital $(40 \mathrm{mg} / \mathrm{kg}$ ) via intraperitoneal injection prior to the establishment of CIA. Type II collagen was solubilized in $0.05 \mathrm{M}$ acetic acid to a concentration of $4 \mathrm{mg} / \mathrm{ml}$. Using an electric homogenizer, collagen II was emulsified with equal volume of incomplete Freund's adjuvant (Chondrex, Inc.). CIA model rats were established by immunization with $0.1 \mathrm{ml}$ emulsion subcutaneously injected into the tail base at day 0 and day 7. Rats injected with vehicle (adjuvant alone) were used as controls $(n=7)$.

Isolation and identification of FLSs. FLSs were isolated from synovium samples obtained from CIA rats. The rats were anesthetized using $1 \%$ sodium pentobarbital $(40 \mathrm{mg} / \mathrm{kg})$ via intraperitoneal injection, and then euthanatized by cervical vertebra dislocation before FLSs isolation. FLSs were obtained by $0.2 \%$ collagenase digestion at $37^{\circ} \mathrm{C}$ for $4 \mathrm{~h}$. The synovium tissue was washed five times on ice with PBS containing $1 \%$ ampicillin and streptomycin. The synovium tissue was then sectioned into 1-mm-thick slices which were placed in a plate containing $0.2 \%$ type II collagenase (cat. no. 17101015; Gibco; Thermo Fisher Scientific, Inc.) and then transferred to a $37^{\circ} \mathrm{C}$ incubator for $4 \mathrm{~h}$. Over the process, the supernatant was collected every $60 \mathrm{~min}$ and centrifuged at $290 \mathrm{x} \mathrm{g}$ for $5 \mathrm{~min}$ at room temperature to collect the cell pellet. These procedures were repeated four times. The cells were re-suspended in DMEM (Gibco; Thermo Fisher Scientific, Inc.) complete culture medium containing 10\% FBS (Gibco; Thermo Fisher Scientific, Inc.), and $100 \mathrm{U} / \mathrm{ml}$ of ampicillin and streptomycin. The cells were then filtered through 200-mesh stainless steel filters and seeded in flasks at the density of $1 \times 10^{5}$ cells $/ \mathrm{cm}^{2}$ and cultured at $37^{\circ} \mathrm{C}$ in $5 \% \mathrm{CO}_{2}$ incubator for 3-4 days. Upon reaching $90 \%$ confluence, the cells were passaged. Cells at passage two were used for further experiments. For ELISA, western blotting, and reverse transcription-quantitative PCR (RT-qPCR) experiments, FLSs were seeded in 6-well plates at $2 \times 10^{5}$ cells/well.

ELISA. The content of MCP-1 in the synovial tissue of CIA rats was measured using a rat MCP-1 ELISA kit (cat. no. ab100778; Abcam), according to the manufacturer's protocol. The synovial tissue in all samples were performed in duplicate.

Cell Counting Kit-8 (CCK-8) assay. FLSs were plated at a density of $5 \times 10^{3}$ cells/well in a 96 -well plate with $0.1 \mathrm{ml}$ complete DMEM for $24 \mathrm{~h}$, and then starved for $24 \mathrm{~h}$ in serum-free DMEM medium. MCP-1 (cat. no. 279-MC-010; R\&D Systems, Inc.) was added (at final concentration of 1,10 , $100,200,500$ and $1,000 \mathrm{ng} / \mathrm{ml}$ ) with or without $100 \mathrm{ng} / \mathrm{ml}$ TNF- $\alpha$ (cat. no. 210-TA-005; R\&D Systems, Inc.). The cells were incubated for an additional $48 \mathrm{~h}$ at $37^{\circ} \mathrm{C}$ and then counted using a CCK-8 kit (cat. no. CK04-11; Dojindo Molecular Technologies, Inc.). A total of $10 \mu \mathrm{l}$ kit reagent was added to each well, and the cells were incubated for $2 \mathrm{~h}$ at $37^{\circ} \mathrm{C}$. Cell viability was determined by measuring the absorbance at 450 and $655 \mathrm{~nm}$ with a microplate reader (Bio-Rad Laboratories, Inc.). Each experimental condition was assessed in four wells. To confirm that P38 kinase and PI3K play a role in MCP-1-induced proliferation, FLSs were pretreated with PI3K inhibitor LY294002 [LY; cat. no. 9901; Cell Signaling Technology, Inc. (CST)] and P38 inhibitor SB203580 (SB; cat. no. 5633; CST; final concentrations, 10, 50 and $100 \mu \mathrm{M}$ ) for $1 \mathrm{~h}$ and then stimulated with $200 \mathrm{ng} / \mathrm{ml} \mathrm{MCP-1.}$ 
5-Bromo-2-deoxyuridine (BrdU) assay. The proliferation of FLSs was also assessed using a BrdU cell proliferation ELISA kit (cat. no. ab126556; Abcam). FLSs were treated in the same manner as described in the CCK-8 experiments. BrdU was added to FLSs and then incubated for $2 \mathrm{~h}$ at $37^{\circ} \mathrm{C}$ to incorporate it into their DNA. Paraformaldehyde (4\%) was added for 10 min to fix the cells at $4^{\circ} \mathrm{C}$ and denature the DNA. The solution was then removed and each well washed with PBS three times. The primary detector antibody in the kit was added to each well and incubated at room temperature for $1 \mathrm{~h}$. The cells were washed again with PBS three times. A horseradish peroxidase (HRP)-conjugated secondary antibody included in the kit was added to each well and incubated at room temperature for $30 \mathrm{~min}$. 3,3',5,5'-tetramethylbenzidine solution was added to each well after washing. Stop solution was added after the detection of the signal, and the signal intensity was recorded immediately by measuring the absorbance at 450 and $655 \mathrm{~nm}$ with a microplate reader (Bio-Rad Laboratories, Inc.). Each experimental condition was assessed in four wells.

Transwell assay. FLSs migration ability was evaluated using 24-well chambers (pore size, $8 \mathrm{~mm}$; Corning, Inc.). MCP-1 (200 ng/ml), with or without PI3K and P38 inhibitor (final concentrations, $50 \mu \mathrm{M}$ ), was added to the supernatant. FLSs $\left(1 \times 10^{4}\right.$ cells/well) were seeded in the upper chamber coated with Matrigel, while the lower chamber was filled with $500 \mu \mathrm{l}$ DMEM medium containing $10 \%$ FBS. FLSs that remained on the top of the filters were removed with a cotton swab after $12 \mathrm{~h}$ of incubation at $37^{\circ} \mathrm{C}$. Cells that invaded the Matrigel to the lower chamber of membrane were fixed with $4 \%$ paraformaldehyde at $4^{\circ} \mathrm{C}$ for $20 \mathrm{~min}$ and then stained with crystal violet (cat. no. C0121; Beyotime Institute of Biotechnology) at room temperature for $20 \mathrm{~min}$. The number of migrated cells were manually counted in three random fields.

Western blotting. After MCP-1 stimulation for 0, 15, 30 and $60 \mathrm{~min}$, the total protein was extracted from each group using RIPA lysis buffer (Beyotime Institute of Biotechnology), according to the manufacturer's instructions (24). For the determination of CD31 and VEGF, the cells were incubated with MCP-1 for $48 \mathrm{~h}$ at $37^{\circ} \mathrm{C}$. Protein concentrations were determined using a bicinchoninic acid assay and equal amounts of protein $(20-30 \mu \mathrm{g})$ were resolved by SDS-PAGE (10 or $12 \%)$. Immunoblot analysis was performed as described previously (25). PVDF membranes were incubated with primary antibodies overnight at $4^{\circ} \mathrm{C}$ after blocking with $5 \%$ non-fat milk for $2 \mathrm{~h}$ at room temperature. The primary antibodies used were the following: Phosphorylated-(p-)P38 (1:1,000; cat. no. 4511; CST), P38 (1:1,000; cat. no. 2387; CST), p-PI3K (1:2,000; cat. no. ab182651; Abcam), PI3K (1:500; cat. no. 4249; CST), CD31 (1:1,000; cat. no. ab134168; Abcam), VEGF (1:1,000; cat. no. ab53465; Abcam), TNF- $\alpha$ (1:1,000; cat. no. ab6671; Abcam) and interleukin-1 $\beta$ (IL-1 $\beta ; 1: 2,000$; cat. no. ab150777; Abcam). GAPDH (1:2,000; cat. no. 2118; CST) was used as an internal control.

On the following day, after washing three times with TBS/0.1\% Tween-20, the membranes were incubated with an HRP-conjugated anti-rabbit secondary antibody (cat. no. BA1054; Boster Biological Technology) for $1 \mathrm{~h}$ at room temperature, then washed another three times. The membranes were soaked in an enhanced chemiluminescence reagent (cat. no. AR1191; Boster Biological Technology) for $5 \mathrm{~min}$ at room temperature, and the bands were visualized with X-ray films (VersaDoc imaging systems; Bio-Rad Laboratories, Inc.). The intensity of bands was analyzed using QuantityOne software (version 4.6; Bio-Rad Laboratories, Inc.). Data are presented as the relative expression level, following normalization to the internal loading control GAPDH.

$R T-q P C R$. For the FLSs experiments, $2 \times 10^{5}$ FLSs/well were seeded and stimulated for $24 \mathrm{~h}$ with $200 \mathrm{ng} / \mathrm{ml} \mathrm{MCP-1,}$ $100 \mathrm{ng} / \mathrm{ml}$ TNF- $\alpha$, or $200 \mathrm{ng} / \mathrm{ml} \mathrm{MCP-1}$ with $50 \mu \mathrm{M}$ LY294002 or $50 \mu \mathrm{M}$ SB203580. Total RNA from $2 \mathrm{~g}$ synovial tissue and FLSs were extracted using TRIzol ${ }^{\circledR}$ reagent (Takara Bio, Inc.). RNA $(1 \mu \mathrm{g})$ was reverse transcribed into cDNA using the RevertAid First Strand cDNA Synthesis kit (Takara Bio, Inc.), according to the manufacturer's protocol. qPCR was performed using ABI PRISM 7000 (Applied Biosystems; Thermo Fisher Scientific, Inc.) and SYBR-Green Real-Time PCR Master mix (cat. no. RR430A; Takara Bio, Inc.). The following primer pairs were used for the qPCR: MCP-1 forward, 5'-AGCCAC CTTCATTCCCCAAG-3' and reverse, 5'-CTCCTTGGCCAC AATGGTCT-3'; VEGF forward, 5'-CGGTTCCAGAAGGGA GAGGA-3' and reverse, 5'-CTGGGACCACTTGGCATGG-3'; CD31 forward, 5'-GCCTCACCAAGAGAACGGAA-3' and reverse, 5'-AATTGGATGGCTTGGCCTGA-3'; and GAPDH forward, 5'-ACAGCAACAGGGTGGTGGAC-3' and reverse, 5'-TTTGAGGGTGCAGCGAACTT-3' [Sangon Biotech (Shanghai) Co., Ltd.]. The thermocycling conditions used were as follows: Initial denaturation at $94^{\circ} \mathrm{C}$ for $4 \mathrm{~min}$, followed by $30-35$ cycles at $95^{\circ} \mathrm{C}$ for $30 \mathrm{sec}, 55^{\circ} \mathrm{C}$ for $30 \mathrm{sec}$ and $72^{\circ} \mathrm{C}$ for $30 \mathrm{sec}$. Quantification of the relative expression levels of the target genes was achieved using the formula: $2^{-\Delta \Delta \mathrm{Cq}}$, where $\mathrm{Cq}$ is quantification cycle and $\Delta \Delta \mathrm{Cq}=(\mathrm{Cq}$ of the target gene-Cq of GAPDH) after treatment-(Cq of the target gene-Cq of GAPDH) in the control (26);. Data are presented as relative expression level, which was normalized to GAPDH and the control.

Immunohistochemical analysis. The knee joints of rats were removed and fixed with $10 \%$ paraformaldehyde for 2 days at room temperature and then embedded in paraffin. Paraffin-embedded sections were subsequently cut into 5- $\mu \mathrm{m}$ sections. The sections were first incubated with $3 \%$ peroxyl in methanol for $15 \mathrm{~min}$ at room temperature, then boiled $\left(\sim 100^{\circ} \mathrm{C}\right)$ in citrate buffer solution for $10 \mathrm{~min}$ for antigen retrieval. Following the incubation with 5\% BSA (cat. no. AR1006; Boster Biological Technology) for $20 \mathrm{~min}$ at room temperature, sections were then covered with anti MCP-1 antibody (1:300; cat. no. ab9669; Abcam) overnight at $4^{\circ} \mathrm{C}$. Sections were then incubated with the HRP-conjugated secondary antibody (1:2,000; cat. no. ab205718; Abcam) for $30 \mathrm{~min}$ at room temperature and then incubated with diaminobenzidine for 3-5 min at room temperature to visualize the positive expression of the targeted protein. All sections were counterstained with $5 \%$ hematoxylin for $1 \mathrm{~min}$ at room temperature. Positive cells were observed using a light microscope (magnification, x400; Nikon Corporation).

As for the staining of FLSs with vimentin, $1 \times 10^{6} \mathrm{FLSs} / \mathrm{cm}$ were seeded and cultured for 3 days; subsequently thesupernatant was removed and FLSs were fixed with $4 \%$ paraformaldehyde 

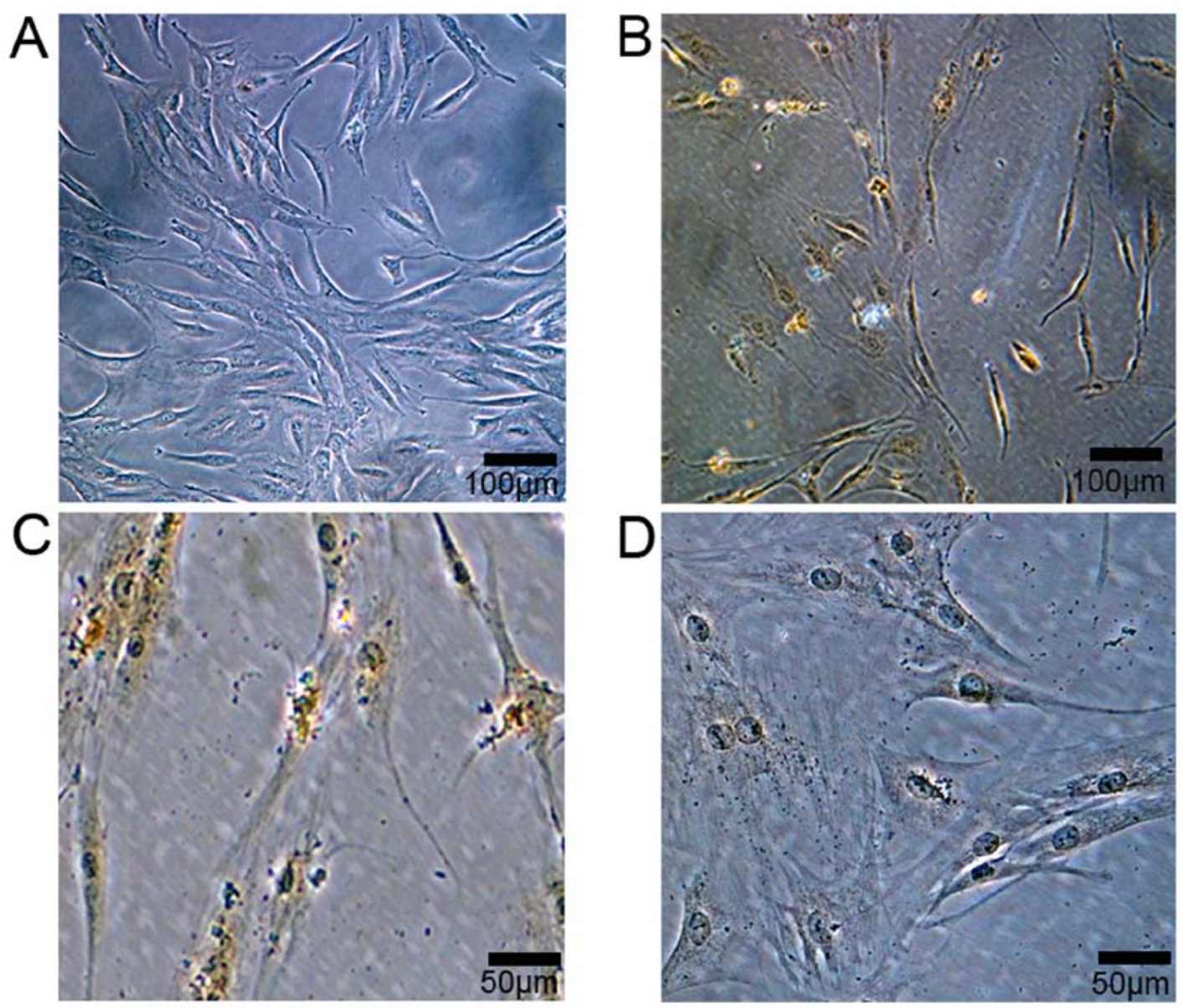

Figure 1. Isolation and identification of fibroblast-like synoviocytes. (A) FLSs exhibited a typical elongated and spindle-like shape. Passage two cells began to adhere and gradually form clusters, and reached $80-90 \%$ confluency within 3-4 days. (B) Purity of FLSs was identified by vimentin staining. (C) Abundant positive staining was observed in FLSs but not in (D) negative controls. Scale bars, 50 or $100 \mu \mathrm{m}$. FLS, fibroblast-like synoviocyte.

for $20 \mathrm{~min}$ at $4^{\circ} \mathrm{C}$. Following permeabilization with Triton $\mathrm{X}$ for $20 \mathrm{~min}$ at room temperature, FLSs were treated with $3 \%$ $\mathrm{H}_{2} \mathrm{O}_{2}$ for $15 \mathrm{~min}$ at room temperature. Following incubation with 5\% BSA for $20 \mathrm{~min}$ at room temperature, the slices were incubated with the anti-vimentin primary antibody $(1: 500$; cat. no. ab92547; Abcam) for $2 \mathrm{~h}$ at $37^{\circ} \mathrm{C}$. Then, the procedures were the same as the immunohistochemical analysis of sections described above.

Statistical analysis. Data are presented as the mean \pm SEM and were analyzed using GraphPad Prism (version 5.0; GraphPad Software, Inc.). ANOVA was used when making comparisons containing multiple groups, and Tukey's test was used as post hoc test. Student's t-test was used to analyze MCP-1 content between the CIA group and control group. $\mathrm{P}<0.05$ was considered to indicate a statistically significant difference.

\section{Results}

Isolation and identification of synovial fibroblasts. With a seeding density of $1 \times 10^{5}$ cells $/ \mathrm{cm}^{2}$, the passage two cells began to adhere and gradually form clusters, and reached $80-90 \%$ confluence within 3-4 days. FLSs appeared spindle-like shaped (Fig. 1A). FLSs were identified by immunohistology, and positive vimentin staining was observed within FLSs
(Fig. 1B and C), while no positive staining was observed in negative controls (Fig. 1D)

Increase in MCP-1 expression in the joints of CIA rats. Using RT-qPCR, the present study demonstrated that the expression levels of MCP-1 in the synovial tissue of CIA rats were significantly increased compared with the control group (Fig. 2A). In addition, ELISA was used to assess the protein expression levels of MCP-1 in synovial tissue from CIA rats, and it was found that the protein expression levels of MCP-1 in the inflamed synovium of CIA rats were also significantly higher compared with controls (3-fold increase; Fig. 2B).

MCP-1 protein expression level was also examined by immunohistology. Numerous lumen structures were observed in the synovial tissue of CIA rats, and broad areas positive for MCP-1 staining were identified in the inflamed synovium (Fig. 2C and D), especially around lumen structures (thin arrow in Fig. 2D). By contrast, MCP-1 staining was rarely observed in the controls (Fig. 2E and F), especially around lumen structures (rough arrow in Fig. 2F).

MCP-1 induces proliferation of FLSs in CIA rats via the activation of the PI3K/P38 pathway. Cell proliferation was analyzed using CCK- 8 and BrdU assay. To investigate the effect of MCP-1 on the viability of FLS cells, FLS cells were treated with increasing doses of MCP-1 (0-1,000 $\mathrm{ng} / \mathrm{ml})$. 
A
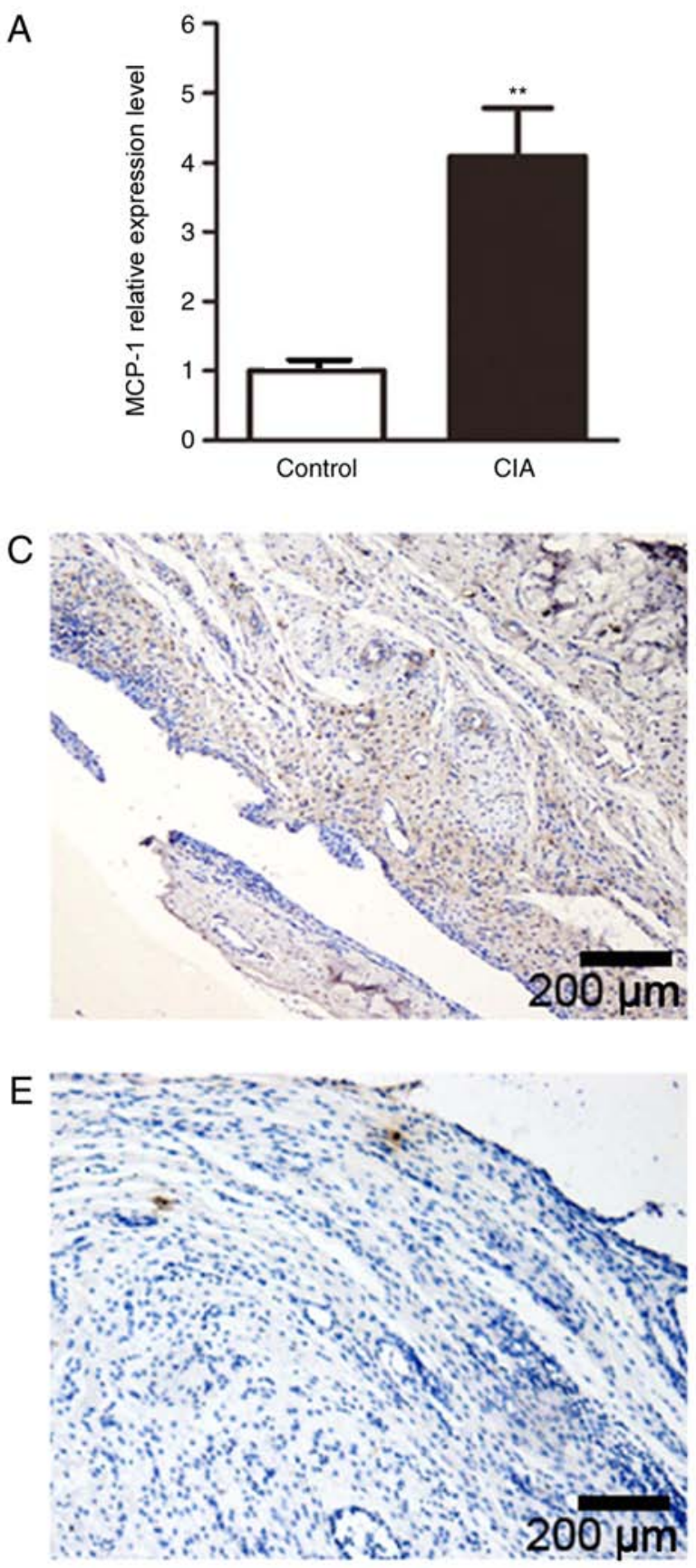

B

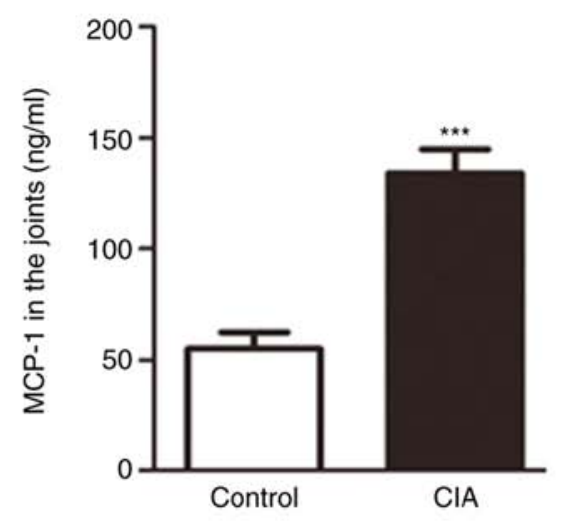

D

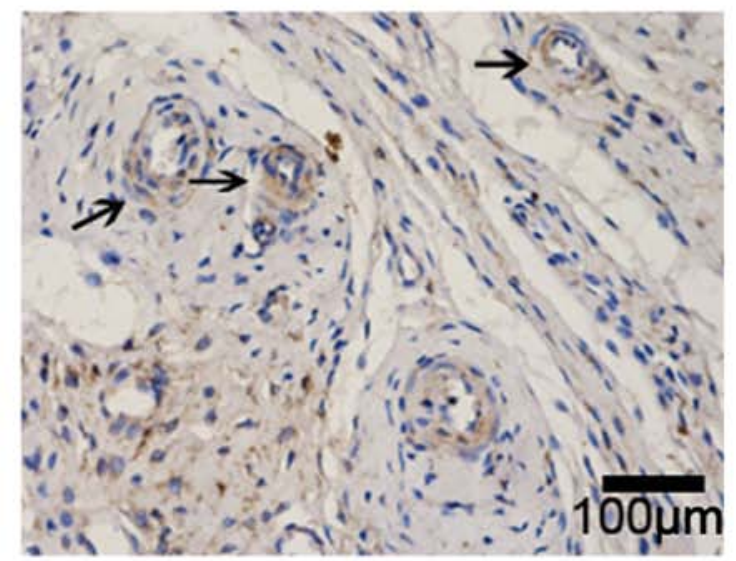

$\mathrm{F}$

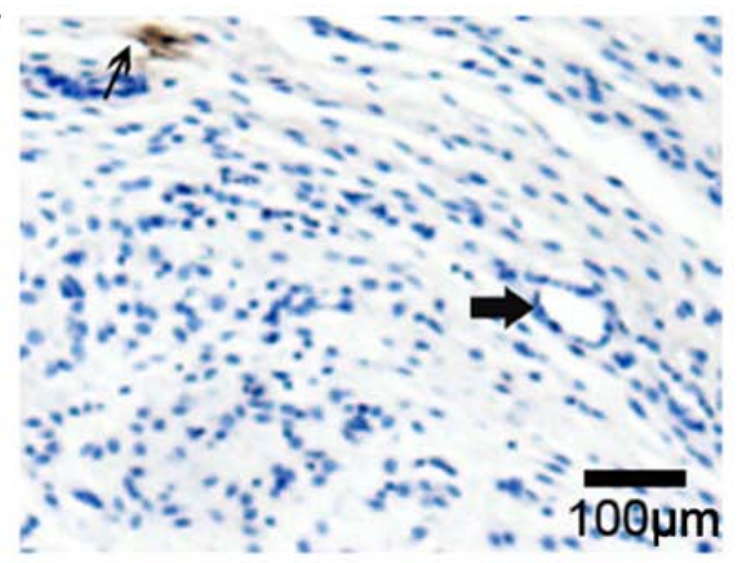

Figure 2. Evaluation of MCP-1 expression in the joints of CIA rats. (A) quantitative PCR results showed that the expression level of MCP-1 in the synovial tissue from CIA rats was greater than in the control. (B) Expression level of MCP-1 in the synovial tissue from CIA rats was assessed by ELISA. A significant upregulation of MCP-1 was found in the inflamed synovial of CIA rats compared with controls (3.5-fold). Immunohistological results showed that there were a lot of lumen structures in the synovial tissue of CIA rats. (C and D) Positive staining of MCP-1 was observed in the inflamed synovium, especially around lumen structures (thin arrows). (E and F) Staining was scattered in the control synovium (thin arrow), whereas there is no positive staining of MCP-1 around the lumen structures in the control group (thick arrow). Scale bars, 100 or $200 \mu \mathrm{m}$. Data are presented as the mean $\pm \mathrm{SEM}$. ${ }^{* *} \mathrm{P}<0.01,{ }^{* * *} \mathrm{P}<0.001 \mathrm{vs}$. control. MCP-1, monocyte chemoattractant protein-1; CIA, collagen-induced arthritis.

MCP-1 promoted the proliferation of FLSs in a dose-dependent manner (Fig. 3A). MCP-1 exerted the maximum effect on the proliferation of FLSs at a concentration of $200 \mathrm{ng} / \mathrm{ml}$ (Fig. 3A), which was then used in the subsequent experiments. This finding was also confirmed by the BrdU test results (Fig. S1). Additive effects of MCP-1 in combination with TNF- $\alpha$ on FLSs proliferation were also found by stimulating FLSs with TNF- $\alpha$ (100 ng/ml), MCP-1 (200 ng/ml) or the two cytokines in combination (Fig. 3B). The present study observed that TNF- $\alpha$ could also promote the proliferation of
FLSs, and increase the proliferation potential of FLSs induced by MCP-1 (Fig. 3B).

The present study analyzed the effect of MCP-1 on the phosphorylation levels of PI3K and P38. Phosphorylation level of PI3K increased 2.68-fold compared to that of untreated samples at 15 min following treatment with MCP-1 (Fig. 3C). One of the PI3K downstream signaling molecules, P38, was analyzed in addition to PI3K in FLSs. The phosphorylation levels of P38 were 2.45- and 4.2-fold higher after 15 and $30 \mathrm{~min}$ of MCP-1 stimulation, respectively, compared with the control groups 
A

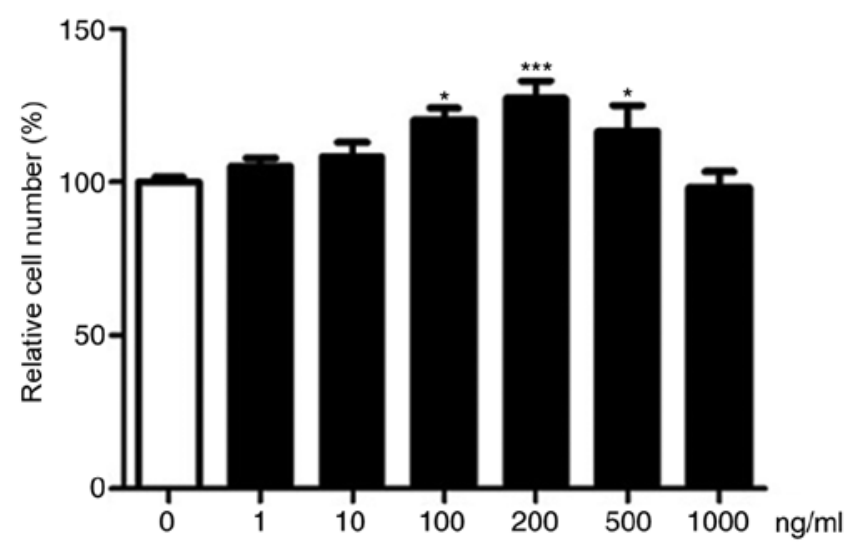

C

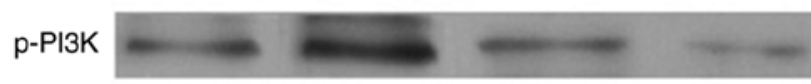

t-PI3K

p-P38

t-P38

GAPDH

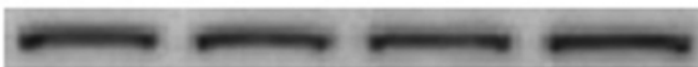

E

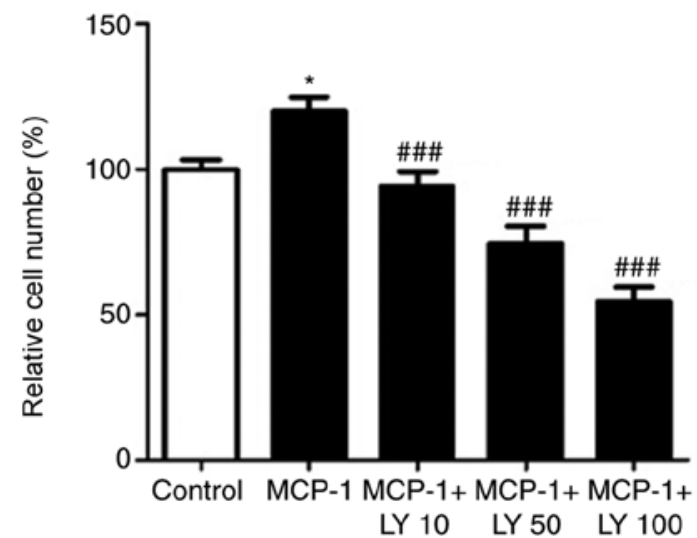

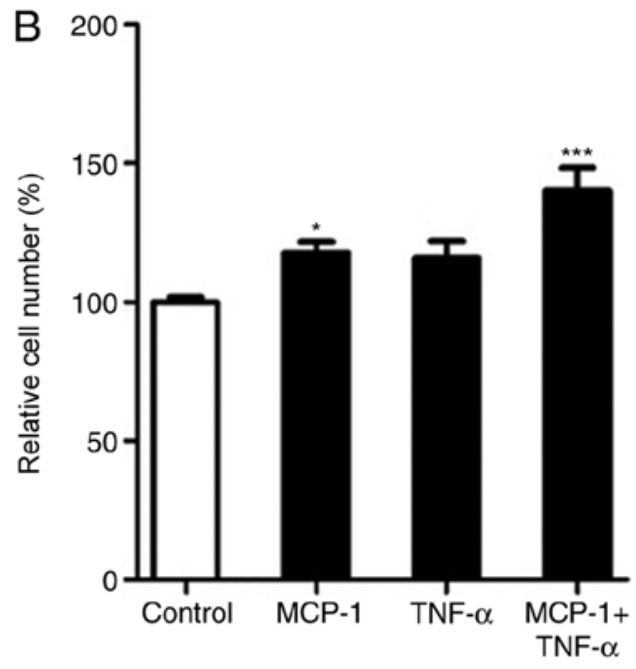

D
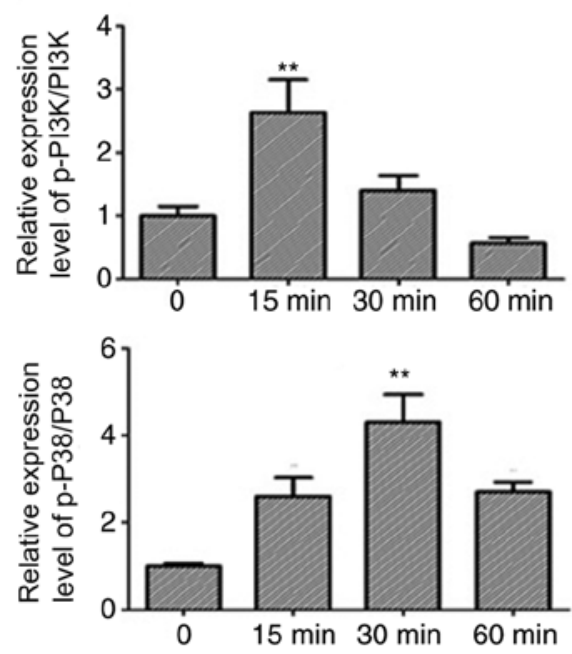

$\mathrm{F}$

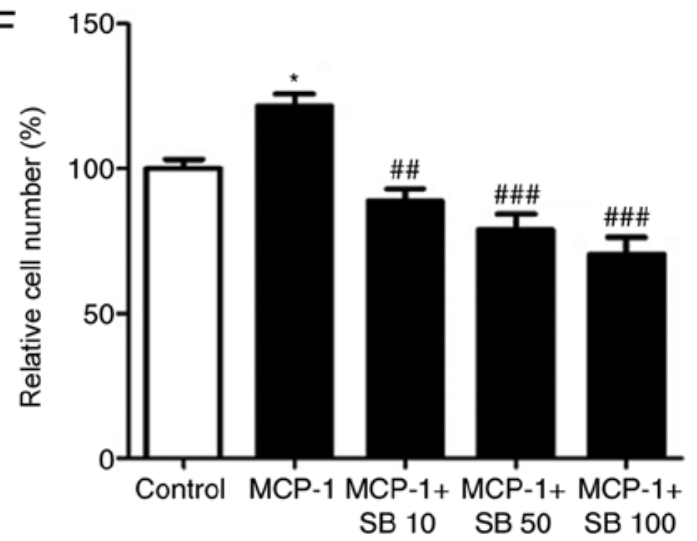

Figure 3. Effect of MCP-1 on the proliferation of FLSs. (A) FLSs were incubated with MCP-1 at 1, 10, 100, 200, 500 and 1,000 ng/ml. Columns show the percentage of the values of cells without MCP-1 treatment. MCP-1 at a concentration of $200 \mathrm{ng} / \mathrm{ml}$ exerted the maximum effect on the proliferation of FLSs. (B) MCP-1 with TNF- $\alpha$ increased the proliferation of FLSs. (C) Total and phosphorylated expression levels of PI3K and P38 at 15, 30 and 60 min following MCP-1 treatment compared with untreated samples. (D) Phosphorylation expression levels relative to total protein expression levels of P38 and PI3K were higher after 15,30 and 60 min of MCP-1 stimulation compared with the control. To test whether PI3K and P38 were involved in the proliferation of FLSs induced by MCP-1, FLSs were pretreated with LY294002 (at 10, 50 and $100 \mu \mathrm{M}$ ) and SB203580 (at 10, 50 and $100 \mu \mathrm{M}$ ) for 30 min prior to MCP-1 stimulation, which was performed for $48 \mathrm{~h}$. The cell proliferation induced by MCP-1 was significantly reduced when incubated with (E) LY and (F) SB in a concentration-dependent manner. Data are presented as the mean $\pm \mathrm{SEM} .{ }^{*} \mathrm{P}<0.05,{ }^{* *} \mathrm{P}<0.01$ and ${ }^{* * *} \mathrm{P}<0.001$ vs. respective control; ${ }^{\# \#} \mathrm{P}<0.01,{ }^{\# \# \#} \mathrm{P}<0.001 \mathrm{vs}$. MCP-1 group. MCP-1, monocytes chemotactic protein 1; FLSs, fibroblast-like synoviocytes; CCK-8, cell counting kit-8; LY, LY294002; SB, SB203580; t-, total; p-, phosphorylated; TNF- $\alpha$, tumor necrosis factor- $\alpha$.

(Fig. 3D). To further examine whether P38/PI3K signaling was involved in the proliferation of FLSs via MCP-1, FLSs were pretreated with SB, aP38 inhibitor (at 10,50 and $100 \mu \mathrm{M}$ ) and LY, a PI3K inhibitor (at 10, 50 and $100 \mu \mathrm{M}$ ) for 30 min prior 

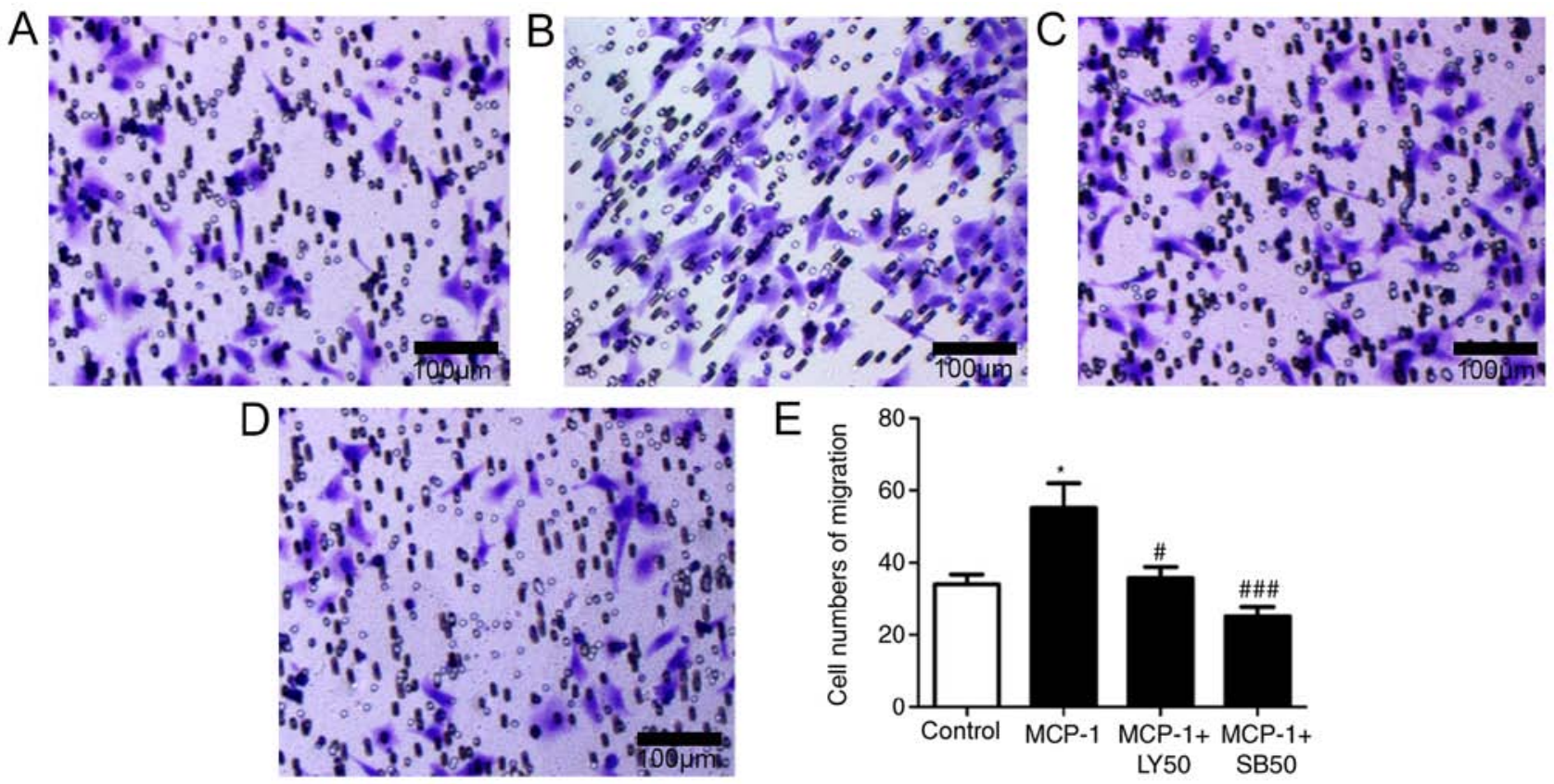

Figure 4. Effect of MCP-1 on the migration of FLSs. In comparison with (A) control, (B) MCP-1 stimulation significantly enhanced migration of FLSs. In addition, MCP-1-induced migration of FLSs was blocked by (C) PI3K inhibitor and (D) P38 inhibitor. (E) Statistical analysis. "P<0.05 vs. control, ${ }^{\#} \mathrm{P}<0.05$,

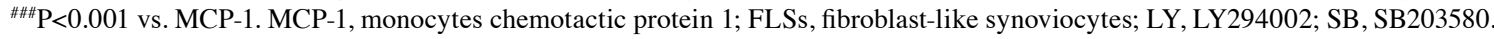

to MCP-1 stimulation. Cell proliferation induced by MCP-1 was significantly reduced when incubated with SB or LY, in a concentration-dependent manner (Fig. 3E and F).

$M C P-1$ promotes the migration of FLSs through the activation of PI3K/P38 pathway. The involvement of MCP-1 in the migration and invasion of FLSs was then investigated. MCP-1 stimulation significantly increased the migration of FLSs (Fig. 4A and B). Additionally, the present study investigated whether PI3K and P38 could regulate FLS migration; the results demonstrated that $\mathrm{MCP}-1$-induced migration of FLSs was significantly blocked by LY and SB (Fig. 4C-E), suggesting that the migration of FLSs induced by MCP-1 was activated by the PI3K and P38 pathway.

MCP-1, and not TNF- $\alpha$, induces differentiation of FLSs through the activation of P38/PI3K pathway. MCP-1 is known to act as a regulator of cell differentiation and proliferation, but, to the best of our knowledge, the role of MCP-1 on the differentiation potential of FLSs towards vascular endothelial cells remains unclear. The results from the present study showed that the protein expression levels of vessel formation biomarker proteins, such as VEGF and CD31, in FLSs were significantly increased after MCP-1 treatment, while TNF- $\alpha$ treatment $(100 \mathrm{ng} / \mathrm{ml})$ was unable to increase their expression levels (Fig. 5A and B). The expression levels of VEGF and CD31 induced by MCP-1 were also significantly reduced by the PI3K and P38 inhibitors SB and LY (Fig. 5C and D). Furthermore, MCP-1 was found to upregulate the RNA expression levels of CD31 and VEGF in FLSs (Fig. S2).

$M C P-1$ induces the expression levels of TNF- $\alpha$ and $I L-1 \beta$. In the present study, it was found that the expression levels of TNF- $\alpha$ and IL-1 $\beta$ were significantly upregulated by treatment from MCP-1 (Fig. 5E and F). The present results suggested that MCP-1 may be involved in the pathogenesis of arthritis, partly through the secretion of TNF- $\alpha$ and IL-1 $\beta$.

\section{Discussion}

RA is a severe and debilitating disease that ultimately results in disability $(1,3)$. The tumor-like proliferation of FLSs is thought to be the major cause of hyperplasia of the synovium and the destruction of joints (24). MCP-1 is involved in tumor progression and metastasis in cancer through its pro-migratory and pro-invasive effects on tumor cells $(20,21,23,27,28)$. Although it has been previously reported that MCP-1 plays a critical role in the development of RA or CIA by affecting monocytes and pro-inflammatory cytokine expression (29), the role of MCP-1 on the behavior of FLSs remains unclear. The present study, to the best of our knowledge, is the first to identify that MCP-1 can promote the proliferation, migration and differentiation potential of FLSs through the P38/PI3K signaling pathway. The results of the present study increased the understanding of the role of MCP-1 in joint destruction in RA and CIA animal models, which may facilitate the development of novel therapeutic strategies.

It was previously reported that MCP-1 secreted by FLSs is involved in RA and bacterial-mediated joint destruction. Scian et al (30) found increased secretion of MCP1 by FLSs in joint damage induced by Brucella abortus infection. A previous study found that lipopolysaccharides can enhance the expression of MCP-1 in cultured FLSs (31). Another previous study found that the expression levels of MCP-1 were high in the inflamed synovium of patients with RA, but were limited in the tissue of normal controls (32), which is partly consistent with the present immunohistological and ELISA results. Additional evidence indicated that MCP-1 could activate FLSs 
A

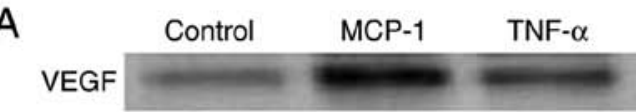

GAPDH

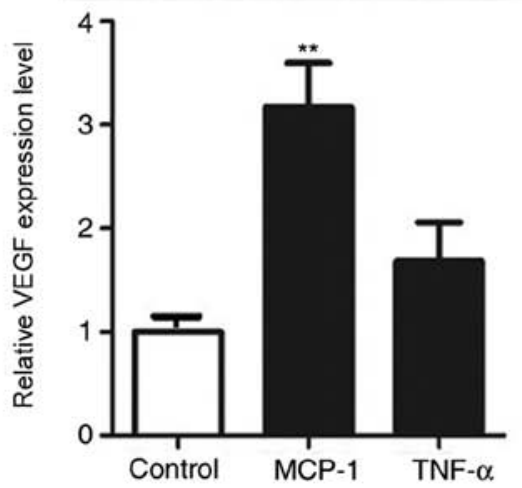

C
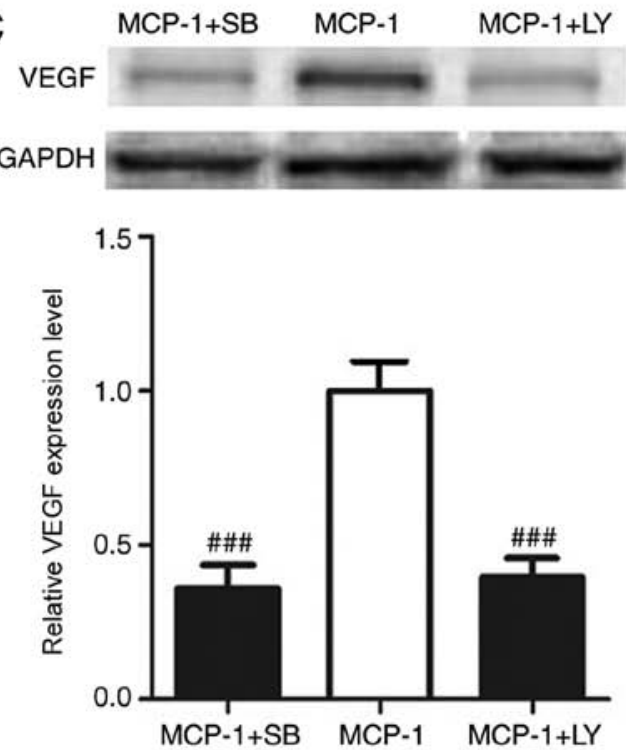

E
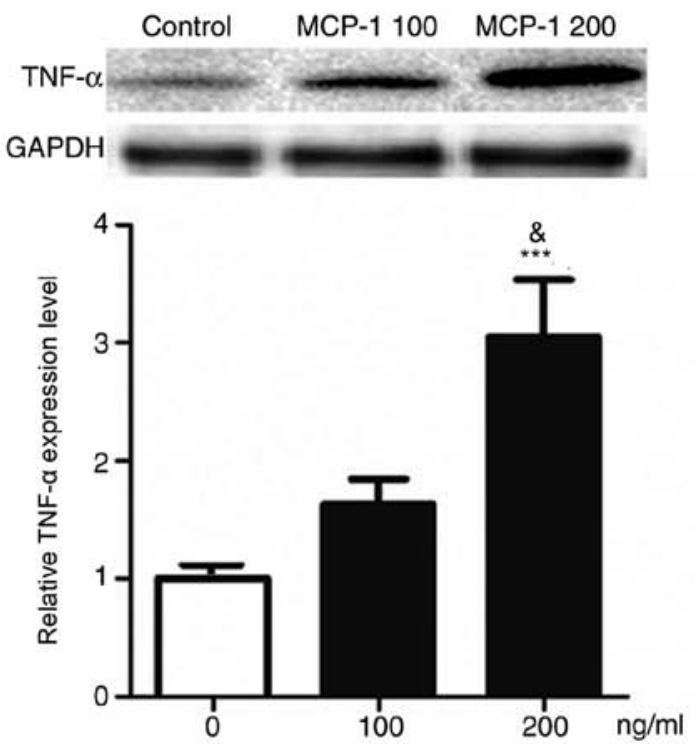

B
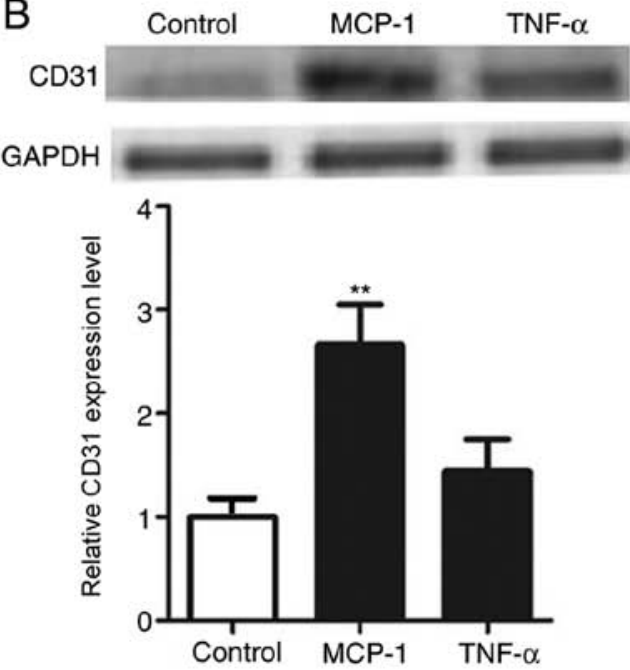

D

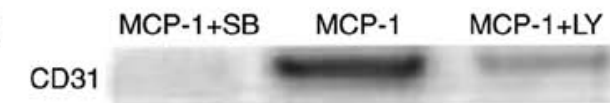

GAPDH
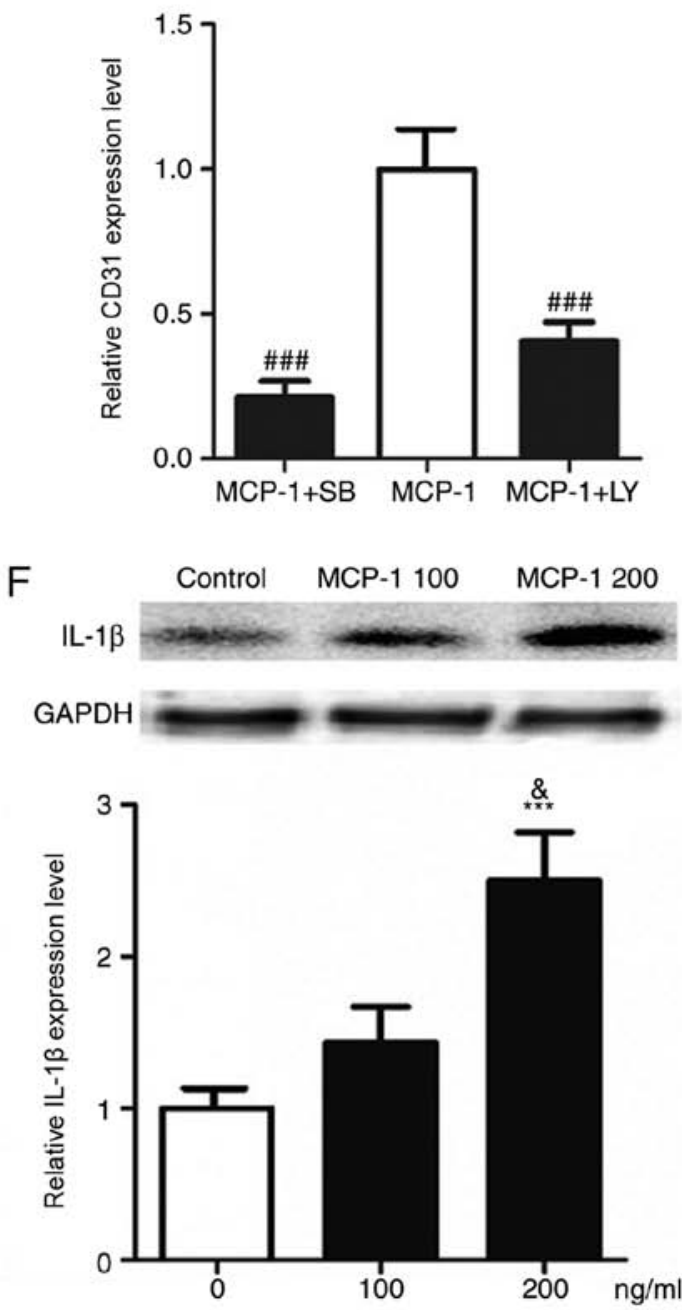

Figure 5. Effect of MCP-1 on the expression level of VEGF, CD31, TNF- $\alpha$ and IL-1 $\beta$ in FLSs. Expression levels of the angiogenesis biomarkers (A) VEGF and (B) CD31 in FLSs increased significantly after treatment with MCP-1, while their expression after TNF- $\alpha$ treatment slightly increased. P38 and PI3K signaling were examined to evaluate their effects on the expression levels of (C) VEGF and (D) CD31. Expression levels of (E) TNF- $\alpha$ and (F) IL-1 $\beta$ were also increased significantly after treatment with MCP-1. Data are presented as the mean $\pm \mathrm{SEM} .{ }^{* *} \mathrm{P}<0.01,{ }^{* * *} \mathrm{P}<0.001$ vs. control group; ${ }^{\# \#} \mathrm{P}<0.001 \mathrm{vs}$. MCP-1 group; ${ }^{\&} \mathrm{P}<0.05$ vs. MCP at $100 \mathrm{ng} / \mathrm{ml}$. MCP-1, monocytes chemotactic protein 1; FLSs, fibroblast-like synoviocytes; SB, SB203580; LY, LY294002; TNF- $\alpha$, tumor necrosis factor- $\alpha$; IL-1 $\beta$, interleukin-1 $\beta$; t-, total; p-, phosphorylated. 
directly, as MCP-1 receptors were found to be expressed in FLSs in patients with RA (33).

However, the effect of MCP-1 on FLSs remains unclear. MCP-1 is a promoter not only of inflammation, but of cell migration and invasion in tumor cells $(20,21,28)$. Therefore, the present study examined the effects of MCP-1 on the proliferation and migration capacity of FLSs, and found that both processes were enhanced by treatment with MCP-1. The present results indicated that MCP-1 induced proliferation and migration of FLSs, and could therefore contribute to severe joint damage. Therefore, the present results provided novel evidence on the association between MCP-1 and the aggressive features of FLSs. The present findings may have important clinical significance. Elevated MCP-1 content in joints may lead to more severe cartilage and bone damage. Therefore, MCP-1 may be a novel indicator of disease severity, which is supported by the fact that blood MCP-1 levels may be useful in monitoring RA activity (12). Therefore, targeting MCP-1 or its receptor may facilitate the suppression of RA progression.

In addition, angiogenesis of the pannus is important during the pathological process of RA (34). VEGF and CD31 are biomarkers of endothelial cell differentiation, secreted by a variety of cell types such as fibroblasts, endothelial cells and osteoblasts, and serve important roles in inducing the differentiation of vascular endothelial cells $(35,36)$. It was also reported that $\mathrm{MCP}-1$ could serve as a direct mediator of angiogenesis by increasing $\mathrm{C}-\mathrm{C}$ chemokine receptor type 2 expression in the endothelium (21). Consistent with these studies, the present study showed that the expression of MCP-1 was mainly located around the lumen structures in the synovium, and in vitro experiments indicated that MCP-1 could induce the expression of VEGF and CD31 in FLSs. Therefore, MCP-1 may contribute to the formation of capillaries in the pannus through increasing the expression of VEGF and CD31 in FLSs. Another possible explanation is that MCP-1 may promote FLSs differentiation into endothelial cells, as FLSs were shown to have the potential to differentiate into osteoblasts and chondrocytes $(37,38)$. Nevertheless, additional studies are required to explore the role of MCP-1 in the angiogenesis in the pannus formed during RA.

PI3K and P38 pathways have been reported to be involved in inflammation activation and cell differentiation induced by MCP-1 (39). MCP-1 has been reported to promote the proliferation of smooth muscle cells by activating PI3K $(40,41)$ and myoblast cell proliferation by activating P38 (42). There are multiple crosstalk between P38 and PI3K pathways, and various previous studies showed that proliferation and pro-inflammatory mechanisms are activated by $\mathrm{PI} 3 \mathrm{~K} / \mathrm{P} 38$ pathway $(42,43)$. In the present study, the accumulation of p-PI3K was observed following MCP-1 treatment at $15 \mathrm{~min}$, while P38 phosphorylation was activated by MCP-1 treatment after $30 \mathrm{~min}$. Collectively, the present results suggested that MCP-1 could alter the phenotype of FLSs through the PI3K/P38 pathway.

In conclusion, the present study suggested that MCP-1 may promote the proliferation and migration of FLSs. In addition, MCP-1 induced FLSs differentiation potential towards vascular endothelial cells through the PI3K/P38 pathway, which contributed to the formation of the pannus in CIA rats. The present study described a novel possible mechanism of
MCP-1 in joint destruction in RA, a finding which may be beneficial to the identification of novel disease indicators and the development of novel therapeutic strategies.

\section{Acknowledgements}

We gratefully acknowledge the help of Dr Zhiyun Feng (Department of Orthopedic Surgery, The First Affiliated Hospital, College of Medicine, Zhejiang University), who provided valuable suggestions to this study.

\section{Funding}

The present study was supported by The Program Science and Technology Department of Zhejiang Province (grant no. LGF19H060012) and Medicine and Health Science and Technology Plan in Zhejiang province (grant no. 2017KY053).

\section{Availability of data and materials}

The datasets used and/or analyzed during the current study are available from the corresponding author on reasonable request

\section{Authors' contributions}

XL and XT conceived and designed the study. The experiments were performed by HZe, XT, KW and HZh. XL, XT and PG analyzed the data and wrote the manuscript. All authors read and approved the final manuscript.

\section{Ethics approval and consent to participate}

All experiments were carried out following the Guide for the Care and Use of Laboratory Animals of the National Institutes of Health and all the procedures were pre-approved by the Review Board of the First Affiliated Hospital of Medical College of Zhejiang University.

\section{Patient consent for publication}

Not applicable.

\section{Competing interests}

The authors declare that they have no competing interests.

\section{References}

1. Aletaha D, Funovits J and Smolen JS: Physical disability in rheumatoid arthritis is associated with cartilage damage rather than bone destruction. Ann Rheum Dis 70: 733-739, 2011.

2. Feng Z, Zeng S, Wang Y, Zheng Z and Chen Z: Bisphosphonates for the prevention and treatment of osteoporosis in patients with rheumatic diseases: A systematic review and meta-analysis. PLoS One 8: 57-57, 2013.

3. Scott DL, Smith C and Kingsley G: Joint damage and disability in rheumatoid arthritis: An updated systematic review. Clin Exp Rheumatol 21 (5 Suppl 31): S20-S27, 2003.

4. Feng ZY, He ZN, Zhang B, Li YQ, Guo J, Xu YL, Han MY and Chen Z: Adenovirus-mediated osteoprotegerin ameliorates cartilage destruction by inhibiting proteoglycan loss and chondrocyte apoptosis in rats with collagen-induced arthritis. Cell Tissue Res 362: 187-199, 2015. 
5. Sharif K, Jumah F, Oskouian R and Tubbs RS: Rheumatoid arthritis in review: Clinical, anatomical, cellular and molecular points of view. Clin Anat 31: 216-223, 2018.

6. Bustamante MF, Garcia-Carbonell R, Whisenant KD and Guma M: Fibroblast-like synoviocyte metabolism in the pathogenesis of rheumatoid arthritis. Arthritis Res Ther 19: 110, 2017.

7. Noss EH and Brenner MB: The role and therapeutic implications of fibroblast-like synoviocytes in inflammation and cartilage erosion in rheumatoid arthritis. Immunol Rev 223: 252-270, 2008.

8. Guo J, Zhao W, Cao X, Yang H, Ding J, Ding J, Tan Z, Ma X, Hao C, Wu L, et al: SIRT1 promotes tumor-like invasion of fibroblast-like synoviocytes in rheumatoid arthritis via targeting TIMP1. Oncotarget 8: 88965-88973, 2017.

9. Wang $\mathrm{H}$, Chen W, Wang L, Li F, Zhang $\mathrm{C}$ and $\mathrm{Xu}$ L: Tumor necrosis factor receptor-associated factor 6 promotes migration of rheumatoid arthritis fibroblast-like synoviocytes. Mol Med Rep 11: 2761-2766, 2015.

10. Shi Y, Wu Q, Xuan W, Feng X, Wang F, Tsao BP, Zhang M and Tan W: Transcription factor SOX 5 promotes the migration and invasion of fibroblast-like synoviocytes in part by regulating MMP-9 expression in collagen-induced arthritis. Front Immunol 9: $749,2018$.

11. Lochhead RB, Ordonez D, Arvikar SL, Aversa JM, Oh LS, Heyworth B, Sadreyev R, Steere AC and Strle K: Interferon-gamma production in Lyme arthritis synovial tissue promotes differentiation of fibroblast-like synoviocytes into immune effector cells. Cell Microbiol 21: e12992, 2019.

12. Liou LB, Tsai WP, Chang CJ, Chao WJ and Chen MH: Blood monocyte chemotactic protein-1 (MCP-1) and adapted disease activity Score28-MCP-1: Favorable indicators for rheumatoid arthritis activity. PLoS One 8: e55346, 2013

13. Zheng Y, Sun L, Jiang T, Zhang D, He D and Nie H: TNF $\alpha$ promotes Th17 cell differentiation through IL- 6 and IL-1 $\beta$ produced by monocytes in rheumatoid arthritis. J Immunol Res 2014: 385352 , 2014.

14. Darrieutort-Laffite C, Boutet MA, Chatelais M, Brion R, Blanchard F, Heymann D and Le Goff B: IL-1 $\beta$ and TNFo promote monocyte viability through the induction of GM-CSF expression by rheumatoid arthritis synovial fibroblasts. Mediators Inflamm 2014: 241840, 2014

15. Zucali JR, Dinarello CA, Oblon DJ, Gross MA, Anderson L and Weiner RS: Interleukin 1 stimulates fibroblasts to produce granulocyte-macrophage colony-stimulating activity and prostaglandin E2. J Clin Invest 77: 1857-1863, 1986.

16. Satish LD, Sergey K, Shohreh A and Bassel ES: Monocyte chemoattractant protein-1 (MCP-1): An overview. J Interferon Cytokine Res 29: 313-326, 2009.

17. Rantapää-Dahlqvist S, Boman K, Tarkowski A and Hallmans G: Up regulation of monocyte chemoattractant protein-1 expression in anti-citrulline antibody and immunoglobulin $\mathrm{M}$ rheumatoid factor positive subjects precedes onset of inflammatory response and development of overt rheumatoid arthritis. Ann Rheum Dis 66: 121-123, 2007

18. Ogata H, Takeya M, Yoshimura T, Takagi $\mathrm{K}$ and Takahashi $\mathrm{K}$ : The role of monocyte chemoattractant protein-1 (MCP-1) in the pathogenesis of collagen-induced arthritis in rats. J Pathol 182: 106-114, 2015.

19. Shiva S, Proudfoot AE, Park CC, Volin MV, Haines GK, Woods JM, Aikens CH, Handel TM and Pope RM: Inhibition of monocyte chemoattractant protein-1 ameliorates rat adjuvant-induced arthritis. J Immunol 180: 3447-3456, 2008.

20. Kuper C, Beck FX and Neuhofer W: Autocrine MCP-1/CCR2 signaling stimulates proliferation and migration of renal carcinoma cells. Oncol Lett 12: 2201-2209, 2016.

21. Salcedo R, Ponce ML, Young HA, Wasserman K, Ward JM, Kleinman HK, Oppenheim JJ and Murphy WJ: Human endothelia cells express CCR2 and respond to MCP-1: Direct role of MCP-1 in angiogenesis and tumor progression. Blood 96: 34-40, 2000

22. Zhu Z, Huang P, Chong Y, George SK, Wen B, Han N, Liu Z, Kang L and Lin N: Nucleus pulposus cells derived IGF-1 and MCP-1 enhance osteoclastogenesis and vertebrae disruption in lumbar disc herniation. Int J Clin Exp Pathol 7: 8520-8531, 2014.

23. Chen X, Wang Y, Nelson D, Tian S, Mulvey E, Patel B, Conti I, Jaen J and Rollins BJ: CCL2/CCR2 regulates the tumor microenvironment in HER-2/neu-driven mammary carcinomas in mice. PLoS One 11: e0165595, 2016.

24. Du J, Zhang F and Guo J: miR137 decreases proliferation, migration and invasion in rheumatoid arthritis fibroblastlike synoviocytes. Mol Med Rep 17: 3312-3317, 2018.
25. Feng ZY, He ZN, Zhang B and Chen Z: Osteoprotegerin promotes the proliferation of chondrocytes and affects the expression of ADAMTS-5 and TIMP-4 through MEK/ERK signaling. Mol Med Rep 8: 1669-1679, 2013.

26. Livak KJ and Schmittgen TD: Analysis of relative gene expression data using real-time quantitative PCR and the 2(-Delta Delta C(T)) method. Methods 25: 402-408, 2001

27. Dutta P, Sarkissyan M, Paico K, Wu Y and Vadgama JV: MCP-1 is overexpressed in triple-negative breast cancers and drives cancer invasiveness and metastasis. Breast Cancer Res Treat 170: 477-486, 2018

28. Lu E, Su J, Zhou Y,Zhang C and Wang Y: CCL20/CCR6 promotes cell proliferation and metastasis in laryngeal cancer by activating p38 pathway. Biomed Pharmacother 85: 486-492, 2017.

29. Goldbergova MP, Lipkova J, Pavek N, Pavek N, Gatterova J, Vasku A, Soucek M and Nemec P: RANTES, MCP-1 chemokines and factors describing rheumatoid arthritis. Mol Immunol 52: 273-278, 2012.

30. Scian R, Barrionuevo P, Giambartolomei GH, De Simone EA, Vanzulli SI, Fossati CA, Baldi PC and Delpino MV: Potential role of fibroblast-like synoviocytes in joint damage induced by Brucella abortus infection through production and induction of matrix metalloproteinases. Infecti Immun 79: 3619-3632, 2011.

31. Andreassen SM, Berg LC, Nielsen SS, Kristensen AT and Jacobsen S: mRNA expression of genes involved in inflammation and haemostasis in equine fibroblast-like synoviocytes following exposure to lipopolysaccharide, fibrinogen and thrombin. BMC Vet Res 11: 141, 2015.

32. Zhang L, Yu M, Deng J, Lv X, Liu J, Xiao Y, Yang W, Zhang Y and $\mathrm{Li} \mathrm{C}$ : Chemokine signaling pathway involved in CCL2 expression in patients with rheumatoid arthritis. Yonsei Med J 56: 1134-1142, 2015.

33. Cho ML, Yoon BY, Ju JH, Jung YO, Jhun JY, Park MK, Park SH, Cho CS and Kim HY: Expression of CCR2A, an isoform of MCP-1 receptor, is increased by MCP-1, CD40 ligand and TGF-beta in fibroblast like synoviocytes of patients with RA. Exp Mol Med 39: 499-507, 2007.

34. Paleolog EM: Angiogenesis in rheumatoid arthritis. Arthritis Res 4 (Suppl 3): S81-S90, 2002.

35. Hamilton JL, Nagao M, Levine BR, Chen D, Olsen BR and Im HJ: Targeting VEGF and its receptors for the treatment of osteoarthritis and associated pain. J Bone Miner Res 31: 911-924, 2016.

36. Choe JY, Lee SJ, Park SH and Kim SK: Tacrolimus (FK506) inhibits interleukin-1 $\beta$-induced angiopoietin-1, Tie-2 receptor, and vascular endothelial growth factor through down-regulation of JNK and p38 pathway in human rheumatoid fibroblast-like synoviocytes. Joint Bone Spine 79: 137-143, 2012.

37. Osta B, Roux JP, Lavocat F, Pierre M, Ndongo-Thiam N, Boivin G and Miossec P: Differential effects of IL-17A and TNF- $\alpha$ on osteoblastic differentiation of isolated synoviocytes and on bone explants from arthritis patients. Front Immunol 6: 151, 2015.

38. Hms W, Toyota K, Kim S, Fang J, Bwalya EC, Hosoya K and Okumura M: Differentiation potential of synoviocytes derived from joints with cranial cruciate ligament rupture and medial patella luxation in dogs. Res Vet Sci 114: 370-377, 2017.

39. Biswas SK and Sodhi A: Effect of monocyte chemoattractant protein-1 on murine bone marrow cells: Proliferation, colony-forming ability and signal transduction pathway involved. Int J Immunopathol Pharmacol 15: 183-194, 2002.

40. Fougerat A, Smirnova NF, Gayral S, Malet N, Hirsch E, Wymann MP, Perret B, Martinez LO, Douillon M and Laffargue M: Key role of PI3K $\gamma$ in monocyte chemotactic protein-1-mediated amplification of PDGF-induced aortic smooth muscle cell migration. Br J Pharmacol 166: 1643-1653, 2012.

41. Ming Z, Yawei L, Mingmin B, Yutaka K, Jiahuai H and Eaton JW: Vascular smooth muscle cell proliferation requires both p38 and BMK1 MAP kinases. Arch Biochem Biophys 400: 199-207, 2002.

42. Liu S, Gao F, Wen L, Ouyang M, Wang Y, Wang Q, Luo L and Jian Z: Osteocalcin induces proliferation via positive activation of the PI3K/Akt, P38 MAPK pathways and promotes differentiation through activation of the GPRC6A-ERK1/2 pathway in C2C12 myoblast cells. Cell Physiol Biochem 43: 1100-1112, 2017.

43. Huang BP, Lin CH, Chen HM, Lin JT, Cheng YF and Kao SH: AMPK activation inhibits expression of proinflammatory mediators through downregulation of PI3K/p38 MAPK and NF- $\kappa \mathrm{B}$ signaling in murine macrophages. DNA Cell Biol 34: 133-141, 2015. 